\title{
Identification of candidate target genes of genomic aberrations in esophageal squamous cell carcinoma
}

\author{
TIAN-YUN SHEN, LI-LI MEI, YUN-TAN QIU and ZHI-ZHOU SHI \\ Faculty of Medicine, Kunming University of Science and Technology, Kunming, Yunnan 650500, P.R. China
}

Received June 26, 2015; Accepted July 12, 2016

DOI: $10.3892 / \mathrm{ol} .2016 .4947$

\begin{abstract}
The aim of the present study was to identify the candidate target genes of genomic aberrations in esophageal squamous cell carcinoma (ESCC). Array comparative genomic hybridization (CGH) and quantitative polymerase chain reaction were applied to analyze the copy number changes and expression level of candidate genes, respectively. Integrative analysis revealed that homozygous deletions of cyclin-dependent kinase inhibitor (CDKN) 2A and CDKN2B and gains of fascin actin-bundling protein 1 (FSCN1) and homer scaffolding protein 3 (HOMER3) occurred frequently in ESCC. The results demonstrated that the homozygous deletion of CDKN2A or CDKN2B was significantly associated with lymph node metastasis. Notably, the expression of CDKN2A and CDKN2B was lower in dysplasia than in normal esophageal epithelium. We also observed that the copy number increase of FSCN1 was significantly associated with pT, pN and pStage, and that the gain of HOMER3 was significantly linked with $\mathrm{pN}$ and pStage. We further revealed that FSCN1 and HOMER3 were overexpressed in ESCC, and that their overexpression was correlated with copy number increase. In conclusion, CDKN2A, CDKN2B, FSCN1 and HOMER3 are candidate cancer-associated genes and may play a tumorigenic role in ESCC.
\end{abstract}

\section{Introduction}

Esophageal squamous cell carcinoma (ESCC) is one of the most malignant types of cancer and is ranked as the sixth most common cause of cancer-associated mortality in the world, with a high incidence in China $(1,2)$. Although diagnostic methods and cancer therapies have been improved in recent years, the prognosis remains poor due to widespread

Correspondence to: Dr Zhi-Zhou Shi, Faculty of Medicine, Kunming University of Science and Technology, 727 South Jingming Road, Kunming, Yunnan 650500, P.R. China

E-mail: zhizhoushi@126.com

Key words: esophageal squamous cell carcinoma, cyclin-dependent kinase inhibitor $2 \mathrm{~A}$ and $2 \mathrm{~B}$, fascin actin-bundling protein 1 , homer scaffolding protein 3 lymph node metastasis and frequent distant metastasis. Therefore, the identification and understanding of candidate target genes of genomic aberrations underlying esophageal carcinogenesis and metastasis may provide a new treatment target in ESCC.

ESCC is a multi-step process, and genomic aberration is a characteristic attribute. Several studies have identified that losses of 9p21.3, 16p13.3 and 18q22-qter and gains of $5 \mathrm{p} 15,7 \mathrm{p} 22.1,11 \mathrm{q} 13.3$ and $19 \mathrm{p} 13.11$ were the most frequent genomic aberrations in ESCC (3-5). Functional studies identified a number of candidate target driver genes of genomic aberration. For example, genomic loss and hypermethylation of nc886 (noncoding RNA) were detected in ESCC, and ectopically expressed nc886 could inhibit proliferation of ESCC cells (6). Togashi et al (7) also reported that oral cancer overexpressed 1 (ORAOV1) located at 11q13 was amplified in $53 \%$ of ESCC patients, and its amplification was significantly associated with poor differention status. Overexpression of ORAOV1 could enhance tumorigenicity and tumor growth (7). Thus, the identification of candidate tumor-associated genes is crucial in revealing the mechanism of tumorigenesis of esophageal cancer.

In the present study, we integratively analyzed the array comparative genomic hybridization $(\mathrm{CGH})$ data and observed that homozygous deletions of cyclin-dependent kinase inhibitor (CDKN) 2A (9p21.3) and CDKN2B (9p21.3) and gains of fascin actin-bundling protein 1 (FSCN1) (7p22.1) and homer scaffolding protein 3 (HOMER3) (19p13.11) occurred frequently in ESCC. We further analyzed the correlations between the copy number changes of CDKN2A, CDKN2B, FSCN1, HOMER3 and clinical factors, and investigated the expression level of these genes in ESCC samples.

\section{Materials and methods}

Patients and samples. Freshly resected tissues from 115 ESCC patients were collected at the Department of Pathology, Cancer Hospital, Chinese Academy of Medical Sciences, Beijing, China. All of the esophageal cancer patients were treated with radical surgery, and none of them received any treatment prior to surgery. Representative tumor regions were excised by experienced pathologists and immediately stored at $-70^{\circ} \mathrm{C}$ until use.

Biopsy tissues were taken from symptom-free patients during endoscopic screening for esophageal cancer in Linzhou, 
Table I. Correlations between copy number changes of genes and clinical factors.

\begin{tabular}{|c|c|c|c|c|c|c|c|c|c|c|c|c|}
\hline \multirow[b]{2}{*}{ Factors } & \multicolumn{3}{|c|}{ CDKN2A } & \multicolumn{3}{|c|}{ CDKN2B } & \multicolumn{3}{|c|}{ FSCN1 } & \multicolumn{3}{|c|}{ HOMER3 } \\
\hline & HD & No HD & P-value & HD & No HD & P-value & Gain & No gain & P-value & Gain & No gain & P-value \\
\hline Gender & & & 0.764 & & & 0.777 & & & 0.387 & & & 1.000 \\
\hline Male & 20 & 43 & & 23 & 40 & & 25 & 38 & & 14 & 49 & \\
\hline Female & 4 & 12 & & 5 & 11 & & 4 & 12 & & 3 & 13 & \\
\hline Age & & & 0.804 & & & 0.098 & & & 1.000 & & & 0.102 \\
\hline$\leq 60$ & 9 & 24 & & 8 & 25 & & 12 & 21 & & 4 & 29 & \\
\hline$>60$ & 15 & 31 & & 20 & 26 & & 17 & 29 & & 13 & 33 & \\
\hline $\mathrm{pT}$ & & & 0.586 & & & 0.795 & & & 0.002 & & & 0.130 \\
\hline $\mathrm{T} 1-\mathrm{T} 2$ & 8 & 14 & & 7 & 15 & & 2 & 20 & & 2 & 20 & \\
\hline T3-T4 & 16 & 41 & & 21 & 36 & & 27 & 30 & & 15 & 42 & \\
\hline $\mathrm{pN}$ & & & 0.003 & & & 0.011 & & & 0.022 & & & 0.013 \\
\hline N0 & 6 & 35 & & 9 & 32 & & 10 & 31 & & 4 & 37 & \\
\hline $\mathrm{N} 1$ & 18 & 20 & & 19 & 19 & & 19 & 19 & & 13 & 25 & \\
\hline pStage & & & 0.207 & & & 0.146 & & & 0.000 & & & 0.000 \\
\hline I-II & 12 & 37 & & 14 & 35 & & 9 & 40 & & 4 & 45 & \\
\hline III & 12 & 18 & & 14 & 16 & & 20 & 10 & & 13 & 17 & \\
\hline pGrade & & & 0.371 & & & 0.233 & & & 0.282 & & & 0.284 \\
\hline $\mathrm{G} 1$ & 9 & 13 & & 11 & 11 & & 11 & 11 & & 5 & 17 & \\
\hline $\mathrm{G} 2$ & 12 & 30 & & 13 & 29 & & 14 & 28 & & 11 & 31 & \\
\hline G3 & 3 & 12 & & 4 & 11 & & 4 & 11 & & 1 & 14 & \\
\hline
\end{tabular}

CDKN, cyclin-dependent kinase inhibitor; FSCN1, fascin actin-bundling protein 1; HOMER3, homer scaffolding protein 3; HD, homozygous deletion.

China, which is a well-recognized high-risk area for ESCC. During endoscopy, the entire esophagus was visually examined and biopsies were taken from all focal lesions. If no focal lesions were detected, a standard site in the mid-esophagus was sampled.

All the samples used in this study were residual specimens following diagnostic sampling. Every patient signed separate informed consent forms for sampling and molecular analysis. The clinicopathological characteristics of patients are shown in Table I. This study was approved by the Ethics Committee of Kunming University of Science and Technology (Kunming, Yunnan, China)

Microarray data analysis. We integratively analyzed the array CGH data of 79 ESCC cases using Genomic Workbench (Agilent Technologies, Santa Clara, CA, USA) and MD-SeeGH (www.flintbox.ca). Genomic Workbench was used to calculate the $\log _{2}$ ratio for every probe and identify genomic aberrations. The mean $\log _{2}$ ratio of all probes in a chromosome region between 0.25 and 0.75 was classified as a genomic gain, $>0.75$ as an amplification, $\leq 0.25$ as a hemizygous loss, and $\leq 0.75$ as homozygous deletion.

Quantitative polymerase chain reaction ( $q P C R)$. qPCR was used to detect the expression level of candidate genes. The PCR reactions were performed in a total volume of $20 \mu 1$, including $10 \mu \mathrm{l} 2 \mathrm{X}$ Power SYBR ${ }^{\circledR}$-Green PCR master mix
(Applied Biosystems, Warrington, UK), $2 \mu \mathrm{l}$ cDNA (5 ng/ $\mu \mathrm{l}$ ) and $1 \mu \mathrm{l}$ primer mix (10 $\mu \mathrm{M}$ each). The PCR amplification and detection were carried out in a LightCycler 480 II (Roche Applied Science, Manheim, Germany) as follows: initial denaturation at $95^{\circ} \mathrm{C}$ for $10 \mathrm{~min} ; 40$ cycles of $95^{\circ} \mathrm{C}$ for $15 \mathrm{sec}$ and $60^{\circ} \mathrm{C}$ for $1 \mathrm{~min}$. The relative expression was calculated using the comparative $\mathrm{CT}$ method. The expression of the target gene normalized to an endogenous reference (GAPDH) and relative to the calibrator was given by the formula $2^{-\Delta \Delta C q} . \Delta C T$ was calculated by subtracting the average GAPDH CT from the average $\mathrm{CT}$ of the gene of interest. The ratio defines the level of relative expression status of the target gene to that of GAPDH. The following primer pairs were used for the PCR assay: CDKN2A forward, 5'-CTTCCTGGACACGCT GGTG-3', CDKN2A reverse, 5'-AATCGGGGATGTCTG AGGGA-3'; CDKN2B forward, 5'-CGGGGACTAGTGGAG AAGGTG-3', CDKN2B reverse, 5'-CCATCATCATGACCT GGATCGC-3'; FSCN1 forward, 5'-CAAAAAGTGTGCCTT CCGTACC-3', FSCN1 reverse, 5'-CCCATTCTTCTTGGA GGTCACA-3'; HOMER3 forward, 5'-CCAAGGACCAGG AGATTCAGAC-3', HOMER3 reverse, 5'-AGCTCACTCAGC TCAAACAGG-3'; GAPDH forward, 5'-AAATCCCATCAC CATCTTCCAG-3', GAPDH reverse, 5'-GAGTCCTTCCAC GATACCAAAGTTG-3'.

Statistical analysis. Statistical analyses were conducted using Student's t-tests and Chi-square tests using the statistical 


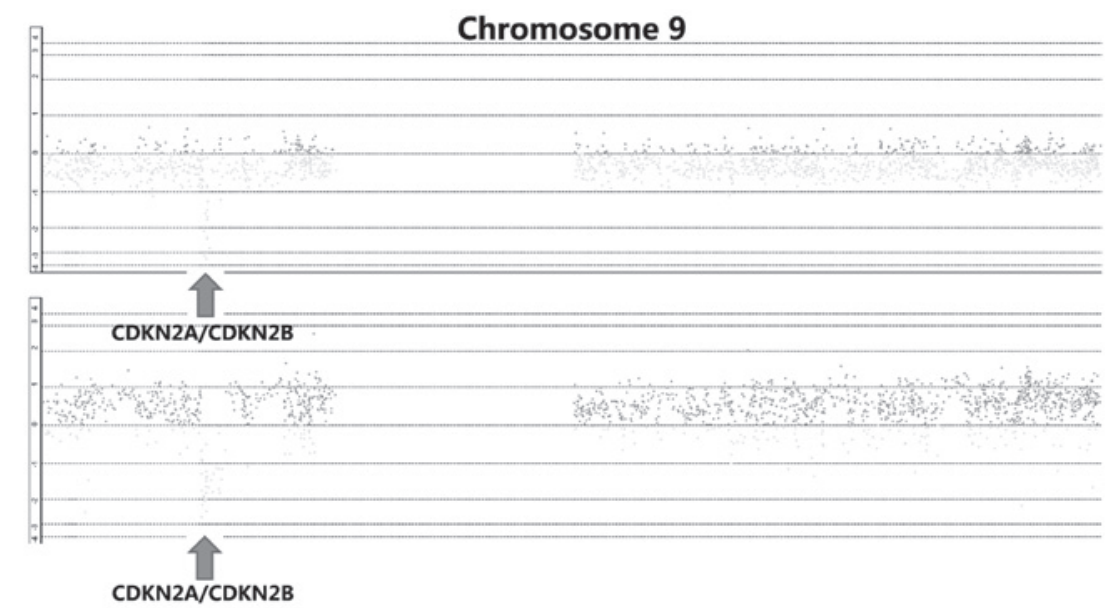

Figure 1. Homozygous deletions of cyclin-dependent kinase inhibitor (CDKN) 2A and CDKN2B in esophageal squamous cell carcinoma.
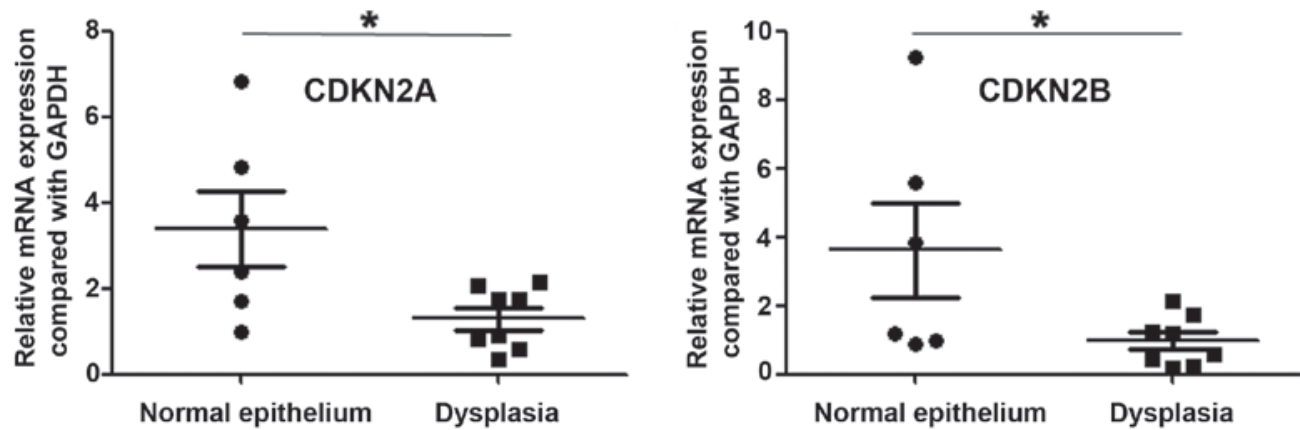

Figure 2. Expression levels of cyclin-dependent kinase inhibitor (CDKN) $2 \mathrm{~A}$ and CDKN2B in dysplasia and normal esophageal epithelium. " $\mathrm{P}<0.05$.

software SPSS version 15.0 (SPSS, Inc., Chicago, IL, USA). $\mathrm{P}<0.05$ was considered to indicate a statistically significant difference.

\section{Results}

Homozygous deletion of CDKN2A and CDKN2B in ESCC. By integrative analysis of array CGH data from 79 ESCC cases, we observed that CDKN2A and CDKN2B were homozygously deleted in $18.6 \%$ of cases (Fig. 1). We further analyzed the correlations between copy number decreases of CDKN2A as well as CDKN2B and clinical parameters, and observed that homozygous deletion of CDKN2A or CDKN2B was significantly associated with lymph node metastasis $(\mathrm{P}=0.003$ and $\mathrm{P}=0011$, respectively; Table I). There were no correlations between homozygous deletion of CDKN2A or CDKN2B and gender, age, pT, pStage or pGrade (Table I). Most significantly, we analyzed the expression of CDKN2A and CDKN2B in precancerous lesions, and observed that the expression of these two genes was lower in dysplasia than in normal esophageal epithelium $(\mathrm{P}=0.024$ and $\mathrm{P}=0.048$, respectively; Fig. 2).

Gains of FSCN1 and HOMER3 in ESCC. By integrative analysis of array CGH data from 79 ESCC cases, we observed that gains of FSCN1 and HOMER3 were detected in 41 and $80 \%$ of patients, respectively (Fig. 3). We further analyzed the correlations between gains of FSCN1 or
HOMER 3 and clinical factors, and observed that gain of FSCN1 was significantly associated with $\mathrm{pT}, \mathrm{pN}$ and $\mathrm{pStage}$ $(\mathrm{P}=0.002, \mathrm{P}=0.022$ and $\mathrm{P}=0.000$, respectively; Table I). In addition, gain of HOMER3 was significantly linked with $\mathrm{pN}$ and pStage $(\mathrm{P}=0.013$ and $\mathrm{P}=0.000$, respectively; Table I). We further revealed through qPCR assay that FSCN1 and HOMER3 were overexpressed in ESCC, and the expression level in patients with gains was significantly higher than that in patients without gains (Fig. 4).

\section{Discussion}

Genomic aberrations are one of the mechanisms resulting in gene dysfunction, and contribute to carcinogenesis and tumor progression. Differentially expressed genes associated with DNA copy number changes may be candidate targets of amplifications or homozygous deletions, and play significant roles in tumorigenesis and the development of cancer (8).

9 p21.3 is the most common loss in numerous types of cancer, including glioblastoma, esophageal cancer and pancreatic cancer $(9,10)$, and is also the most frequent early event in the tumorigenesis of Epstein-Barr virus-associated nasopharyngeal carcinoma (11). CDKN2A and CDKN2B were identified as the driver genes of 9p21.3 loss. CDKN2A and CDKN2B are frequently inactivated in a number of cancer types. In lung cancer, CDKN2A is frequently inactivated via homozygous deletions, the methylation of the promoter region, or point mutations (12). In rectal cancer, Kohonen-Corish et al 
A

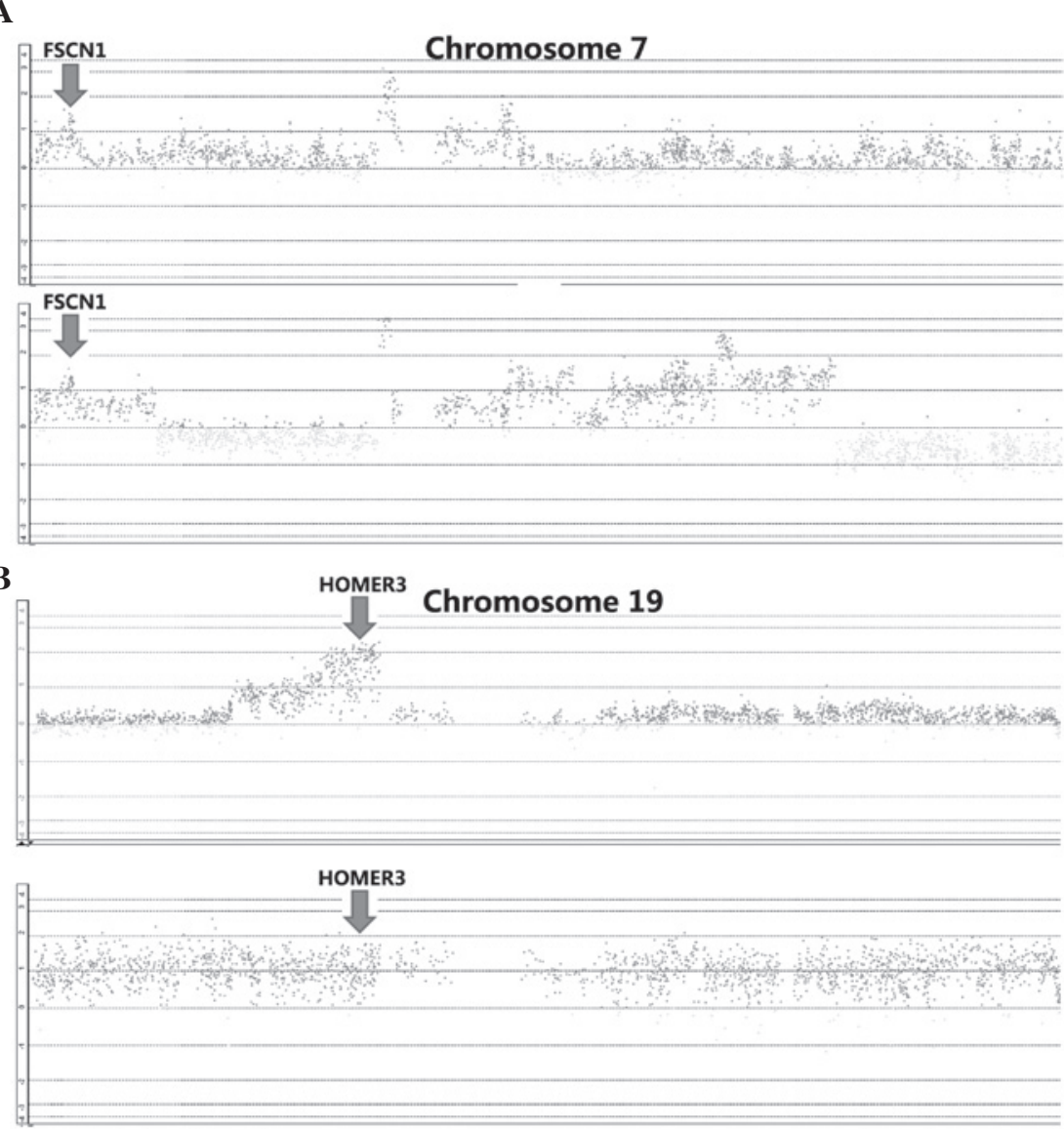

Figure 3. Gains of fascin actin-bundling protein 1 (FSCN1) (A) and homer scaffolding protein 3 (HOMER3) (B) in esophageal squamous cell carcinoma.

A

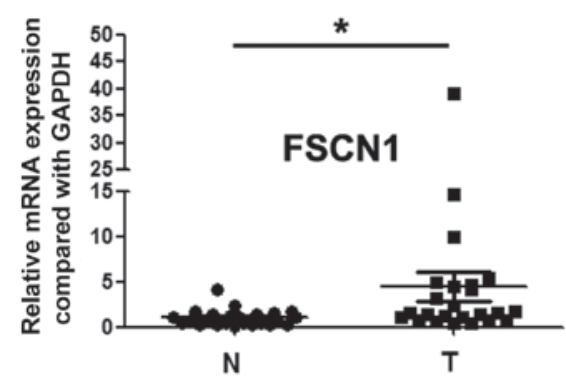

C

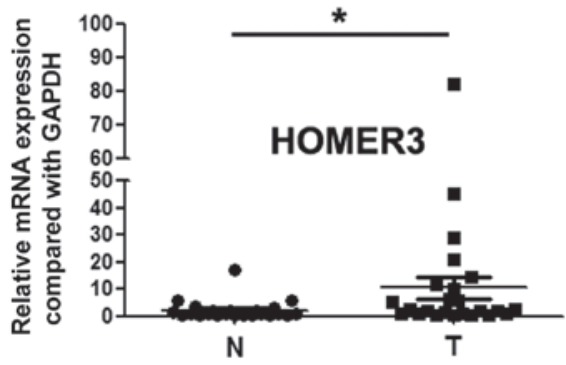

B

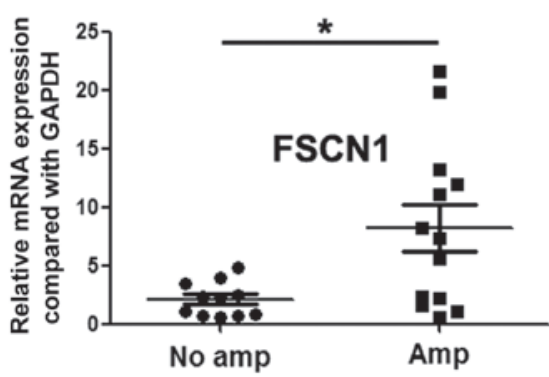

D

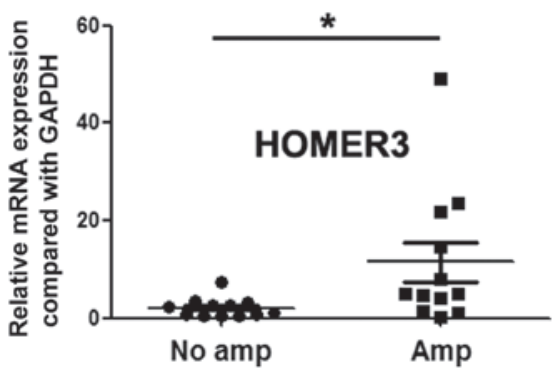

Figure 4. Expression of fascin actin-bundling protein 1 (FSCN1) and homer scaffolding protein 3 (HOMER3) in esophageal squamous cell carcinoma. (A) Expression of FSCN1 in tumor tissues (T) and paracancerous tissues (N); (B) expression of FSCN1 in patients with and without amplification; (C) expression of HOMER3 in tumor tissues (T) and paracancerous tissues (N); (D) expression of HOMER3 in patients with and without amplification. "P<0.05.

observed that CDKN2A methlytion occurred in $20 \%$ of patients, and that CDKN2A methlytion was associated with poor overall survival (13). CDKN2A hypermethylation is also associated with lymphovascular invasion, lymph 
node metastasis and proximal tumor location in colorectal cancer (14). In ovarian cancer, deletion of CDKN2A is also a common event (15). Our study identified that homozygous deletion of CDKN2A or CDKN2B was significantly associated with lymph node metastasis. Most significantly, the expression of CDKN2A and CDKN2B was lower in dysplasia than in normal esophageal epithelium. These results indicate that CDKN2A and CDKN2B may play a significant role in the early formation of esophageal cancer.

Our study also revealed that FSCN1 and HOMER3, which were gained in ESCC, were overexpressed, and higher expression levels of these two genes were associated with copy number increase. The literature reveals that the expression of FSCN1 is an independent poor prognostic factor according to a multivariate analysis, and co-expression with MMP14 correlates with the poorest overall survival in esophageal cancer. The knockdown of FSCN1 inhibits the proliferation and invasion of ESCC cells (16). Chen et al (17) reported that FSCN1 was overexpressed in colorectal cancers, and was associated with cancer cell progression. Hanker et al (18) observed that lower FSCN1 expression was associated with significantly poorer overall survival in epithelial ovarian cancer. In tumors, FSCN1 could be directly targeted and regulated by miR-133a, miR-133b, miR-143 and miR-145 (19-22). Fuse et al (23) further revealed that restoration of miR-145 expression suppresses cell proliferation, migration and invasion in prostate cancer by targeting FSCN1. HOMER3 is a member of the cytoplasmic scaffolding proteins family, and regulates transcription and plays an essential role in the development and differentiation of certain tissues, including muscle and nervous systems (24-26). HOMER3 is overex6pressed in acute myeloid leukemia (AML), and decreased expression of HOMER3 is associated with poor prognosis in AML $(27,28)$. Li et al (29) further reported that forced expression of HOMER3 in K562 cells could inhibit proliferation, influence the cell cycle, and affect apoptosis induced by $\mathrm{As} 2 \mathrm{O} 3$ via inhibition of $\mathrm{Bcl}-2$ expression. However, the roles of FSCN1 and HOMER3 were previously unclear in esophageal carcinogenesis.

In summary, our study suggested that CDKN2A, CDKN2B, FSCN1 and HOMER3 were candidate cancer-associated genes and may play a tumorigenic role in ESCC.

\section{Acknowledgements}

This study was funded by the National Natural Science Foundation of China (grant no. 81460425), the Yunnan Provincial Research Foundation for Basic Research, China (grant no. 2013FD012), the Foundation for the Talents of Kunming University of Science and Technology (grant no. KKSY201226099) and Yunnan Provincial Engineering Center of Translational Cancer Medicine (grant no. 2011DH011).

\section{References}

1. Parkin DM, Bray F, Ferlay J and Pisani P: Global cancer statistics, 2002. CA Cancer J Clin 55: 74-108, 2005.

2. Ferlay J, Soerjomataram I, Dikshit R, Eser S, Mathers C, Rebelo M, Parkin DM, Forman D and Bray F: Cancer incidence and mortality worldwide: sources, methods and major patterns in GLOBOCAN 2012. Int J Cancer 136: E359-E386, 2015.
3. Yen CC, Chen YJ, Chen JT, Hsia JY, Chen PM, Liu JH, Fan FS, Chiou TJ, Wang WS and Lin CH: Comparative genomic hybridization of esophageal squamous cell carcinoma: correlations between chromosomal aberrations and disease progression/prognosis. Cancer 92: 2769-2777, 2001.

4. Shi ZZ, Liang JW, Zhan T, Wang BS, Lin DC, Liu SG, Hao JJ, Yang H, Zhang Y, Zhan QM, et al: Genomic alterations with impact on survival in esophageal squamous cell carcinoma identified by array comparative genomic hybridization. Genes Chromosomes Cancer 50: 518-526, 2011.

5. Hirasaki S, Noguchi T, Mimori K, Onuki J, Morita K, Inoue H, Sugihara K, Mori M and Hirano T: BAC clones related to prognosis in patients with esophageal squamous carcinoma: an array comparative genomic hybridization study. Oncologist 12: 406-417, 2007.

6. Lee HS, Lee K, Jang HJ, Lee GK, Park JL, Kim SY, Kim SB, Johnson BH, Zo JI, Lee JS and Lee YS: Epigenetic silencing of the non-coding RNA nc886 provokes oncogenes during human esophageal tumorigenesis. Oncotarget 5: 3472-3481, 2014.

7. Togashi Y, Arao T, Kato H, Matsumoto K, Terashima M, Hayashi H, de Velasco MA, Fujita Y, Kimura H, Yasuda T, et al: Frequent amplification of ORAOV1 gene in esophageal squamous cell cancer promotes an aggressive phenotype via proline metabolism and ROS production. Oncotarget 5: 2962-2973, 2014.

8. Negrini S, Gorgoulis VG and Halazonetis TD: Genomic instability - an evolving hallmark of cancer. Nat Rev Mol Cell Biol 11: 220-228, 2010

9. Riehmer V, Gietzelt J, Beyer U, Hentschel B, Westphal M, Schackert G, Sabel MC, Radlwimmer B, Pietsch T, Reifenberger $\mathrm{G}$, et al: Genomic profiling reveals distinctive molecular relapse patterns in IDH1/2 wild-type glioblastoma. Genes Chromosomes Cancer 53: 589-605, 2014.

10. Shi ZZ, Shang L, Jiang YY, Hao JJ, Zhang Y, Zhang TT, Lin DC, Liu SG, Wang BS, Gong T, et al: Consistent and differential genetic aberrations between esophageal dysplasia and squamous cell carcinoma detected by array comparative genomic hybridization. Clin Cancer Res 19: 5867-5878, 2013.

11. Cheung CC, Chung GT, Lun SW, To KF, Choy KW, Lau KM, Siu SP, Guan XY, Ngan RK, Yip TT, et al: miR-31 is consistently inactivated in EBV-associated nasopharyngeal carcinoma and contributes to its tumorigenesis. Mol Cancer 13: 184, 2014.

12. Tam KW, Zhang W, Soh J, Stastny V, Chen M, Sun H, Thu K, Rios JJ, Yang C, Marconett CN, et al: CDKN2A/p16 inactivation mechanisms and their relationship to smoke exposure and molecular features in non-small-cell lung cancer. J Thorac Oncol 8: 1378-1388, 2013.

13. Kohonen-Corish MR, Tseung J, Chan C, Currey N, Dent OF, Clarke S, Bokey L and Chapuis PH: KRAS mutations and CDKN2A promoter methylation show an interactive adverse effect on survival and predict recurrence of rectal cancer. Int $\mathbf{J}$ Cancer 134: 2820-2828, 2014.

14. Xing X, Cai W, Shi H, Wang Y, Li M, Jiao J and Chen M: The prognostic value of CDKN2A hypermethylation in colorectal cancer: a meta-analysis. Br J Cancer 108: 2542-2548, 2013.

15. Aravidis C, Panani AD, Kosmaidou Z, Thomakos N, Rodolakis A and Antsaklis A: Detection of numerical abnormalities of chromosome 9 and p16/CDKN2A gene alterations in ovarian cancer with fish analysis. Anticancer Res 32: $5309-5313,2012$.

16. Akanuma N, Hoshino I, Akutsu Y, Murakami K, Isozaki Y, Maruyama T, Yusup G, Qin W, Toyozumi T, Takahashi M, et al: MicroRNA-133a regulates the mRNAs of two invadopodiarelated proteins, FSCN1 and MMP14, in esophageal cancer. Br J Cancer 110: 189-198, 2014.

17. Chen MB, Wei MX, Han JY, Wu XY, Li C, Wang J, Shen W and Lu PH: MicroRNA-451 regulates AMPK/mTORC1 signaling and fascin1 expression in HT-29 colorectal cancer. Cell Signal 26: 102-109, 2014.

18. Hanker LC, Karn T, Holtrich U, Graeser M, Becker S, Reinhard J, Ruckhäberle E, Gevensleben H and Rody A: Prognostic impact of fascin-1 (FSCN1) in epithelial ovarian cancer. Anticancer Res 33: 371-377, 2013.

19. Wu ZS, Wang CQ, Xiang R, Liu X, Ye S, Yang XQ, Zhang GH, $\mathrm{Xu}$ XC, Zhu T and Wu Q: Loss of miR-133a expression associated with poor survival of breast cancer and restoration of miR-133a expression inhibited breast cancer cell growth and invasion. BMC Cancer 12: 51, 2012.

20. Qin Y, Dang X, Li W and Ma Q: miR-133a functions as a tumor suppressor and directly targets FSCN1 in pancreatic cancer. Oncol Res 21: 353-363, 2013. 
21. Kano M, Seki N, Kikkawa N, Fujimura L, Hoshino I, Akutsu Y, Chiyomaru T, Enokida H, Nakagawa $M$ and Matsubara $H$ : miR-145, miR-133a and miR-133b: Tumor-suppressive miRNAs target FSCN1 in esophageal squamous cell carcinoma. Int J Cancer 127: 2804-2814, 2010.

22. Liu R, Liao J, Yang M, Sheng J, Yang H, Wang Y, Pan E, Guo W, Pu Y, Kim SJ and Yin L: The cluster of miR-143 and miR-145 affects the risk for esophageal squamous cell carcinoma through co-regulating fascin homolog 1 . PLoS One 7: e33987, 2012.

23. Fuse M, Nohata N, Kojima S, Sakamoto S, Chiyomaru T, Kawakami K, Enokida H, Nakagawa M, Naya Y, Ichikawa T and Seki N: Restoration of miR-145 expression suppresses cell proliferation, migration and invasion in prostate cancer by targeting FSCN1. Int J Oncol 38: 1093-1101, 2011.

24. Xiao B, Tu JC, Petralia RS, Yuan JP, Doan A, Breder CD, Ruggiero A, Lanahan AA, Wenthold RJ and Worley PF: Homer regulates the association of group 1 metabotropic glutamate receptors with multivalent complexes of homer-related, synaptic proteins. Neuron 21: 707-716, 1998.
25. Bortoloso E, Pilati N, Megighian A, Tibaldo E, Sandonà D and Volpe P: Transition of Homer isoforms during skeletal muscle regeneration. Am J Physiol Cell Physiol 290: C711-C718, 2006.

26. Ishiguro $K$ and Xavier R: Homer-3 regulates activation of serum response element in T cells via its EVH1 domain. Blood 103: 2248-2256, 2004.

27. Stirewalt DL, Meshinchi S, Kopecky KJ, Fan W, Pogosova-Agadjanyan EL, Engel JH, Cronk MR, Dorcy KS, McQuary AR, Hockenbery D, et al: Identification of genes with abnormal expression changes in acute myeloid leukemia. Genes Chromosomes Cancer 47: 8-20, 2008.

28. Valk PJ, Verhaak RG, Beijen MA, Erpelinck CA, Barjesteh van Waalwijk van Doorn-Khosrovani S, Boer JM, Beverloo HB, Moorhouse MJ, van der Spek PJ, Löwenberg B and Delwel R: Prognostically useful gene-expression profiles in acute myeloid leukemia. N Engl J Med 350: 1617-1628, 2004

29. Li Z, Qiu HY, Jiao Y, Cen JN, Fu CM, Hu SY, Zhu MQ, Wu DP and Qi XF: Growth and differentiation effects of Homer3 on a leukemia cell line. Asian Pac J Cancer Prev 14: 2525-2528, 2013. 